\title{
A felicidade na voz de estudantes universitários
}

\author{
Happiness in the voice of university students \\ Felicidad en la voz de los universitarios
}

\section{Resumo}

Objetivo: compreender a autopercepção acerca da felicidade por estudantes universitários do curso de enfermagem. Metodologia: trata-se um estudo observacional, transversal, de abordagem qualitativa, para compreender a autopercepção acerca da felicidade por estudantes universitários do curso de enfermagem em uma instituição no centrooeste paulista. A amostra se deu de forma não-probabilística por conveniência, de forma que foi definida pela presença no momento da coleta dos dados e aceitação em participar da pesquisa. A coleta dos dados foi realizada por meio de entrevista gravada, com utilização de questionário semiestruturado elaborado pelos autores. Os dados foram analisados utilizando o referencial metodológico de Análise de Conteúdo. Resultados: participaram 43 (30,2\%), dos 142 (100\%) alunos do curso de Enfermagem na instituição de ensino superior elegida para a realização da mesma. A maioria é do sexo feminino $(93,0 \%)$. De acordo com o método, os dados obtidos nas entrevistas foram agrupados em duas categorias que contêm subcategorias: 1. A felicidade auto percebida por estudantes de graduação em Enfermagem; 2. A felicidade auto percebida e as dimensões que a compõem. Considerações finais: A felicidade, estado considerado positivo, pode interferir significantemente de forma favorável nas atitudes, sentimento este de satisfação e transformação das emoções em valorização da vida, contudo, cada indivíduo tem sua forma de expressar e se relacionar, sendo um parâmetro de relações familiares e sociais ou também para alguns, um parâmetro individualista, destacando que todos os estudantes foram capazes de identificar as razões de sua felicidade ou infelicidade.

Palavras-chave: Felicidade; Estudantes de enfermagem; Saúde mental; Ensino.

\begin{abstract}
Objective: to understand the self-perception about happiness by university students in the nursing course. Methodology: this is an observational, cross-sectional study, with a qualitative approach, to understand the self-perception about happiness by university students of the nursing course in an institution in the Midwest of São Paulo. The sample was non-probabilistic for convenience, so it was defined by the presence at the time of data collection and acceptance to participate in the research. Data collection was carried out through a recorded interview, using a semi-structured questionnaire prepared by the authors. The data were analyzed using the methodological framework of Content Analysis. Results: $43(30.2 \%)$ of the $142(100 \%)$ students of the Nursing course participated in the higher education institution chosen for the same. Most are female (93.0\%). According to the method, the data obtained in the interviews were grouped into two categories that contain subcategories: 1. Self-perceived happiness by undergraduate nursing students; 2. Self-perceived happiness and the dimensions that compose it. Final considerations: Happiness, a state considered positive, can significantly interfere favorably in attitudes, this feeling of satisfaction and transformation of emotions in valuing life, however, each individual has his way of expressing and relating, being a parameter of relationships family and social or also for some, an individualistic parameter, highlighting that all students were able to identify the reasons for their happiness or unhappiness.
\end{abstract}

Keywords: Happiness; Students nursing; Mental health; Teaching.

\section{Resumen}

Objetivo: comprender la autopercepción sobre la felicidad por parte de estudiantes universitarios en el curso de enfermería. Metodología: se trata de un estudio observacional, transversal, con abordaje cualitativo, para comprender la autopercepción sobre la felicidad de estudiantes universitarios de la carrera de enfermería en una institución del Medio Oeste de São Paulo. La muestra fue no probabilística por conveniencia, por lo que se definió por la presencia al momento de la recolección de datos y aceptación para participar en la investigación. La recolección de datos se realizó mediante entrevista grabada, utilizando un cuestionario semiestructurado elaborado por los autores. Los datos fueron analizados 
utilizando el marco metodológico de Análisis de Contenido. Resultados: 43 (30,2\%) de los 142 (100\%) estudiantes del curso de Enfermería participaron en la institución de educación superior elegida para el mismo. La mayoría son mujeres $(93,0 \%)$. Según el método, los datos obtenidos en las entrevistas se agruparon en dos categorías que contienen subcategorías: 1. Felicidad autopercibida por estudiantes de licenciatura en enfermería; 2. Felicidad autopercibida y las dimensiones que la componen. Consideraciones finales: La felicidad, un estado considerado positivo, puede interferir significativamente favorablemente en las actitudes, este sentimiento de satisfacción y transformación de las emociones en la valoración de la vida, sin embargo, cada individuo tiene su forma de expresarse y relacionarse, siendo un parámetro de las relaciones familiares y sociales o también para algunos, un parámetro individualista, destacando que todos los estudiantes fueron capaces de identificar los motivos de su felicidad o infelicidad.

Palabras clave: Felicidad; Estudiantes de enfermería; Salud mental; Ensenãnza.

\section{Introdução}

O conceito de felicidade pode ser abrangente, desde a percepção da vida em geral, dos aspectos mais significativos, do alcance de propósitos mais relevantes, de necessidades e expectativas importantes, e inclui a felicidade como produto do equilíbrio entre sentimentos positivos e negativos (Farsen, Boehs, Ribeiro, Biavati, \& Silva, 2018).

Sobre a percepção da vida em geral, uma importante medida de impacto em saúde se refere a Qualidade de Vida, definida pela Organização Mundial da Saúde como: “[...] a percepção do indivíduo sobre a sua posição na vida, no contexto da cultura e dos sistemas de valores nos quais ele vive, e em relação a seus objetivos, expectativas, padrões e preocupações" (Campos \& Rodrigues Neto, 2008).

Em pesquisas anteriores, indivíduos definiam bem-estar sendo o mesmo que felicidade, tornando-o duplo sentido e causando contradições (Nunes, Lunardi, Rasi, Tu, Aparecido, \& Souza, 2014). De modo geral, definimos que tudo depende da medida em que o indivíduo de forma positiva avalia e preza a vida que leva, sendo parâmetros individual e exclusivo.

Conforme a Organização Mundial de Saúde, o sentimento de felicidade ou bem estar no indivíduo tem melhor perspectiva da sensação de saúde (Pais-Ribeiro, 2012).

A definição concreta é dificultosa, sendo a melhor forma de explicação o questionário sobre o quão são felizes as pessoas, assim obtendo resultados para análise do grau de autopercepção que cada indivíduo leva.

De acordo com Richard Easterlin, mais conhecido como o "Paradoxo de Easterlin": "Em toda a comunidade, quanto mais dinheiro para a pessoa tradicionalmente manifesta-se mais felicidade para a pessoa. Porém, o aumento do faturamento de todos não aumenta a felicidade de todos". Para o mesmo, a resolução está no bem estar pessoal e na comunidade em que ocupam (RIBEIRO, 2015). Contudo, alguns autores divergem a respeito dessa hipótese.

O bem-estar, sinônimo de felicidade e denominado por estados positivos, em estudos desenvolvem-se ao aumento da potencialização, crescimento, realização pessoal e profissional (Farsen, Boehs, Ribeiro, Biavati, \& Silva, 2018).

A enfermagem em sua profissão é propensa em apresentar alto nível de estresse psíquico e físico, sendo predispostos desde sua formação acadêmica. Com o nível de estresse elevado, ficamos em estados considerados negativos, afetando a concentração, motivação, criatividade, a capacidade de alcançar devidos objetivos e principalmente a felicidade. (Osório, 2016).

A importância deste estudo se dá pela necessidade de analisar a felicidade, pois pesquisas comprovam que indivíduos em estados positivos, apresentam melhor desempenho e produtividade em deveres a que são atribuídos, a solucionar problemas que auxilia no desenvolvimento e nas intervenções necessárias para o alcance do equilíbrio saudável nas tomadas de decisões (Farsen, Boehs, Ribeiro, Biavati, \& Silva, 2018), em sua vida e interação social, no relacionamento familiar e o pessoal como aumento da longevidade, melhora da saúde e o bem estar em geral com a melhoria da qualidade de vida.

Desta forma, o indivíduo possuirá benefícios e dominação em diversos aspectos que surgirem em suas vidas, sendo resultante de seu estado mental positivo (Rossini \& França, 2014).

Sendo assim, partimos das seguintes questões que norteiam esta pesquisa: Qual a percepção dos estudantes de 
enfermagem sobre a sua felicidade? A sua vida acadêmica interfere ou proporciona felicidade?

Neste sentido, esse estudo tem por objetivo compreender a autopercepção acerca da felicidade por estudantes universitários do curso de enfermagem.

\section{Metodologia}

Trata-se de um estudo observacional, transversal, de abordagem qualitativa (Pereira, Shitsuka, Parreira, \& Shitsuka, 2018), para compreender a autopercepção acerca da felicidade por estudantes universitários do curso de enfermagem em uma instituição no centro-oeste paulista.

Foram convidados a participar desta pesquisa, os alunos regularmente matriculados no curso de graduação em Enfermagem da referida instituição. A amostra se deu de forma não-probabilística por conveniência, de forma que foi definida pela presença no momento da coleta dos dados e aceitação em participar da pesquisa.

A coleta dos dados foi realizada por meio de entrevista gravada, com utilização de questionário semiestruturado elaborado pelos autores, que versou a respeito da caracterização dos participantes e sobre a percepção da felicidade e das dimensões que podem a influenciar.

Os dados foram analisados utilizando o referencial metodológico de Análise de Conteúdo, em acordo com os passos propostos por Bardin, trabalhando a fala, especificamente a prática da língua, procurando conhecer aquilo que está por trás das palavras sobre as quais expressam, num momento determinado. É a busca de outras realidades por meio das mensagens (Bardin, 2011).

O projeto de pesquisa foi submetido ao Comitê de Ética em Pesquisa da Fundação Educacional do Município de Assis, CAAE 10813019.6.0000.8547, e aprovado com Parecer n. ${ }^{\circ} 3.269 .268$, emitido em 16 de abril de 2019.

\section{Resultados e Discussão}

Nesta pesquisa participaram 43 (30,2\%), dos 142 (100\%) alunos do curso de Enfermagem na instituição de ensino superior elegida para a realização da mesma. A maioria é do sexo feminino, sendo representada por 40 (93,0\%) participantes.

A predominância das mulheres na profissão é um fato histórico, no Perfil da Enfermagem do Brasil publicado pelo COFEN (2017) aponta que 86,2\% são compostas de enfermeiras mulheres e apenas $13,4 \%$ são homens na profissão. Acontecimento decorrente da história e que contribuiu para a desvalorização da profissão, em que as enfermeiras eram constituídas por santas, feiticeiras, prostitutas e heroínas, sendo definida por comportamentos, ideias e crenças.

O quadro de maioria feminina no curso de graduação em Enfermagem é observado em outros locais, como em São José do Rio Preto/SP com 87,88\% (Ribeiro, Bragiola, Eid, \& Pompeo, 2019), em Brasília/DF com 81,3\% (Facioli, Barros, Melo, Ogliari, \& Custódio, 2019), em Porto Alegre/RS com 80\% (Urbanetto, Rocha, Dutra, Maciel, Bandeira, \& Magnago, 2019), em Fortaleza/CE com 94,06\% (Cestari, Barbosa, Florêncio, Pessoa, \& Moreira, 2017), em Florianópolis/SC com 92,5\% (Petry, Padilha, Kuhnen, \& Meirelles, 2019), em Vitoria da Conquista/BA com 83,33\% (Simoes, Penna, Rodrigues, Carinhanha, Pereira, \& Machado, 2019), em Itajubá/MG com 95,45\% (Silva, Alves, \& Fortes, 2019), em Campo Grande/MS com 85,6\% (Eufrazio, Batiston, \& Medeiros, 2019) e em Coari/AM com 68,2\% (Pereira, Reis, \& Oliveira, 2019). Demonstrando que em todo território brasileiro encontram-se predominância de mulheres graduandas de enfermagem.

Sobre a idade, os participantes tinham entre 17 e 52 anos (média de 24,8; mediana 21 e moda 19).

A idade dos entrevistados variou de 17 a 52 anos, já a faixa etária da maioria dos participantes da pesquisa demonstrou ser de 18 a 25 anos, correspondendo a 69,7\% dos entrevistados, idade esta que se destaca nos dados do Instituto Nacional de Estudos e Pesquisas Educacionais Anísio Teixeira que consta a idade média dos estudantes universitários serem de 19 a 23 anos. 
Acontecimentos avaliados em outras pesquisas do tema, porém em locais distintos, como em Brasília/DF que a média de idade foi de 22 anos, sendo sua maioria até 20 anos (49,3\%) (Facioli et al., 2019), em Fortaleza/CE a idade variou de 18 a 49 anos, mas a faixa etária da maioria dos participantes ficou entre 18 e 29 anos (86,2\%) (Cestari et al., 2017), em Florianópolis/SC a idade dos participantes variou de 18 a 37 anos, com faixa etária da maioria de 18 a 23 anos (55\%) (Petry et al., 2019), em Itajubá/MG a faixa etária da maioria foi entre 21 a 25 anos (77,27\%) (Silva et al., 2019), em Campo Grande/MS obteve a média de idade de 21 anos (Eufrazio et al., 2019), e em Coari/AM a faixa etária da maioria foi de 18 a 23 anos (66,9\%) (Pereira et al., 2019). Fatos estes que comprovam que a maioria dos estudantes universitários são jovens e se enquadram nas estatísticas divulgadas nos dados do INEP.

Acerca da orientação sexual, os participantes eram em sua maioria heterossexuais, sendo estes $95 \%$ dos entrevistados.

Na juventude inicia-se o processo de decisões de educação, trabalho, relações afetivas com envolvimentos e descobertas sexuais que muitas vezes sofrem influência dos padrões sociais e culturais devido às desigualdades prejudicando o desenvolvimento psicológico, físico, reprodutivo, social, profissional e sexual do indivíduo, em geral seu bem-estar (SIMÕES et al., 2019).

A orientação sexual foi de 5\% homossexuais, os direitos humanos ainda envolvem relações políticas, conflitos e lutas com impactos sociais. Por vivência pessoal, acreditamos que os dados obtidos não retratam a realidade, este número baixo de homossexuais pode estar relacionado há dificuldade em assumir a orientação sexual devido à discriminação imposta pela sociedade atual. Por isso, sugerimos que sejam realizadas novas pesquisas que investiguem e confirmem esta hipótese e as dificuldades dos estudantes universitários em assumir sua orientação sexual.

O número de estudantes universitários vem crescendo ao longo dos anos, a vida acadêmica dos estudantes de enfermagem pode proporcionar novas percepções acerca das opções sexuais, contribuindo na inserção desta população em conquistar os seus direitos de acesso à educação e de igualdade social, a universidade tem papel fundamental em repassar informações e reflexões acerca da cidadania com inclusão e redução desta desigualdade (Afonso, Rodrigues, \& Oliveira, 2018).

Corroborando com nossa pesquisa, observamos que em Florianópolis/SC 87,5\% se denominaram heterossexuais (Petry et al., 2019) e em Belo Horizonte/MG com 92,4\% dos entrevistados declarados heterossexuais (Afonso et al., 2018).

Sobre a cor de pele, a predominância dos nossos entrevistados foi de $75 \%$ brancos e de minoria $2 \%$ autodeclararam-se de cor de pele preta. A raça ou cor da pele gera influência perante a sociedade, como em disputas no mercado de trabalho, na segurança, justiça, no convívio social e no ambiente escolar e universitário.

Conforme dados do IBGE, entrevistados disseram que a raça ou cor de pele interfere na vida da população. A diversidade de raças humanas encontrada em nossa sociedade não seria um incomodo se não fossem acompanhados por medos e inseguranças dos racismos e preconceitos.

Estas discriminações surgem na sociedade de forma individual e também institucional afetando diretamente a saúde física e mental do indivíduo desde sua adolescência e na vida adulta no âmbito universitário acarretando em problemas pessoais e profissionais. Infelizmente, nos últimos anos, estudos trazem que as discriminações em ambientes universitários vêm aumentando, justificando assim a redução de negros inseridos em graduações. A maioria das discriminações surge devido à aparência física e o nível socioeconômico baixo ou médio (Santos Júnior, Rachkorskyv, Ronzoni, Dogra, \& Dalgalarrondo, 2017).

Corroborando com nossos dados de prevalência e a devida redução de negros ingressos na universidade, em Porto Alegre/RS 78,9\% se autodeclararam brancos (Urbanetto et al., 2019) e em Uberaba/MG 80,2\% declararam cor da pele branca (Carleto, Cornelio, Nardelli, Gaudenci, Haas, \& Pedrosa, 2019).

Portanto, ressaltamos a importância da necessidade da realização de cálculos de proporcionalidade entre as populações conforme a cor de pele, para entendimento da real situação acerca do acesso à universidade conforme essa categorização. Esta 
análise não foi possível ser realizada devido à falta de dados atuais sobre o censo populacional da cidade.

A respeito da situação conjugal, o estado civil dos participantes em sua maioria solteiros (68\%) e os separados (2\%) descreve a real situação da população brasileira, em que estão priorizando e focando em ter uma formação acadêmica e crescimento no mercado de trabalho para posteriormente pensarem em casar e formar uma vida conjugal (Moura, Nobre, Cortez, Campelo, Macedo, \& Silva, 2016).

A vida acadêmica exige novos desafios dos graduandos com mudanças de ambientes, socioculturais, rotinas e responsabilidades, seguindo pela vida profissional em que sua dedicação limita o contato com familiares e amigos (Ribeiro et al.,2019), dificultando nos relacionamentos. Em contrapartida, as não obrigatoriedades familiares do lar facilitam nas tomadas de decisões a respeito do curso escolhido e da profissão (Cestari et al., 2017).

Situação observada também em Porto Alegre/RS onde 79,6\% dos entrevistados eram solteiros (Urbanetto et al., 2019), em Brasília/DF 91,6\% eram solteiros (Facioli et al., 2019), já em São José do Rio Preto/SP 63,26\% eram solteiros (Ribeiro et al., 2019), em Fortaleza/CE 81,3\% dos acadêmicos eram solteiros, sem companheiros (Cestari et al., 2017), em Florianópolis/SC $85 \%$ eram solteiros (Petry et al., 2019), entre outras pesquisas disponíveis que corroboram com os dados obtidos dos participantes entrevistados nesta pesquisa.

Sobre a renda familiar, de 2 a 3 salários mínimos corresponde a $32 \%$ dos entrevistados, seguindo para 1 a 2 salários mínimos com $22 \%$, situação que justifica a presença de elevados graduandos com programas de bolsas para auxiliar em sua formação como fundo de financiamento estudantil (FIES), escola da família, programa de iniciação científica (PIC), entre outros programas da própria instituição. O governo auxilia no ingresso dos estudantes na universidade, porém os recursos pessoais e para formação profissional se tornam insuficientes para suprir as necessidades (Frenhan \& Silva, 2020) e contribuir na qualidade de vida destes estudantes.

Dados similares também em São José do Rio Preto/SP que os estudantes universitários de enfermagem apresentavam renda familiar em sua maioria de 1 a 3 salários mínimos e representavam 39,4\% dos entrevistados (Ribeiro et al., 2019), em Fortaleza/CE que 91,9\% dos entrevistados tinham o curso custeado por terceiros como programas governamentais ou institucionais (40,3\%) ou pelos pais (51,6\%) (Cestari et al., 2019) e em Uberaba/MG que 34,4\% dos entrevistados tinham de 1 a 5 salários mínimos como renda mensal familiar (Carleto et al., 2019).

Os estudos demonstraram que as condições financeiras influenciam diretamente na qualidade de vida das pessoas, pois satisfaz os desejos, agrada as vontades e impacta positivamente na percepção de bem-estar (Carleto et al., 2019).

A respeito da religião dos participantes, a católica foi predominante entre os estudantes universitários, correspondendo a $58 \%$ dos entrevistados.

A religião induz na cultura e na sociedade, suas crenças tem importante significado nos momentos da vida. Porém suas idolatrias se tornam mais sucintos ao surgimento de doenças mentais (Preto, Souza, Sousa, Fernandes, Pereira, \& Cardoso, 2020).

O catolicismo é a religião de maior parte dos brasileiros devido à tradição familiar e a transmissão desta crença religiosa, mas conforme o fortalecimento das escolhas individuais, estas tradições são rompidas e ocorrem as mudanças das religiões, demonstrado por pesquisas do IBGE que nas últimas décadas ocorreu estas modificações com elevado aumento dos evangélicos, atualmente com sentidos e experiências pessoais com respeito a cada crença e as diferentes religiões (MEZZOMO; PÁTARO; BONINI, 2018), como podemos observar que a grande maioria dos entrevistados ainda continua seguindo o catolicismo (58\%), portanto com uma quantidade significativa de evangélicos (30\%). Como em Itajubá/MG que 72,7\% dos entrevistados ainda seguem o catolicismo (Silva et al., 2019).

De acordo com o método, os dados obtidos nas entrevistas foram agrupados em duas categorias que contêm subcategorias. Apresentamos a seguir e discorreremos sobre cada categoria e subcategoria. 


\subsection{A felicidade auto percebida por estudantes de graduação em Enfermagem}

A definição e controle da felicidade abrangem grande carga emotiva, subjetiva, sobretudo, deve ser considerada a dimensão cognitiva, pois entende-se que cada pessoa tem sua maneira de representar a felicidade (Barros-Oliveira, 2010).

Nesse sentido, ao investigar a representação da felicidade, com emprego de questionamento geral: "Você se considera feliz?", 38 (88,4\%) participantes disseram que sim, e justificaram a autoavaliação positiva com base em relações familiares e sociais saudáveis, seguir um projeto de vida e crescimento profissional. Abaixo é transcrito algumas falas dos participantes.

E9 "Sim, porque eu tenho uma família, uma casa, um estudo que estou cursando, um serviço, então eu me considero feliz".

E11 "Sim me considero, porque até o momento que eu cheguei eu me sinto uma pessoa realizada mediante as metas que eu coloquei na minha vida, eu estou conseguindo se realizar".

E16 "Sim, desfruto de uma boa saúde e tenho uma familia que me ama, que precisa de mim e assim vai".

E21 "Sim, porque mesmo com todas as limitações e dificuldades, eu sempre procuro fazer o melhor, acho que então isso me traz felicidade, mesmo com as lutas me traz as conquistas que estou conseguindo em minha vida".

E23 “Sim, porque eu não tenho motivos para não me considerar uma pessoa feliz, eu tenho realizações, objetivos, projetos e isso me faz ser uma pessoa feliz".

A autopercepção sobre a felicidade foi considerada "em partes" por $4(9,3 \%)$ participantes, que afirmam não existir felicidade todo o tempo, e vivenciar problemas de cunho familiar e acadêmico.

E4 "Depende do momento, porque existem alguns momentos este ano que fazem com que a gente não se sinta tão feliz principalmente por estar no $5^{\circ}$ ano da faculdade, a parte da cobrança".

E28 "Às vezes, porque nem todo mundo é feliz o tempo todo".

Ainda, 1 (2,3\%) entrevistado negou ser feliz, com justificativa de não existir felicidade por completo, mas momentos felizes.

E5 "Não, porque falta muita coisa para eu ser feliz. Assim, o meu pensamento de felicidade, a gente vive momentos felizes, a gente não é feliz por completo, a gente vive momentos felizes só".

Junto a essa questão, foi solicitado que os participantes, transformassem seus depoimentos em uma nota de zero a 10 para o limiar de felicidade. As notas variaram de cinco a 10, com média de 8,2 e moda de 8 .

A felicidade é considerada valores não materiais que constitui os parâmetros subjetivos e psicológicos da qualidade de vida, sofrendo alterações conforme as ocorrências ao longo do dia que podem afetar a saúde psicológica do indivíduo (Frenhan \& Silva, 2020).

Denominada como motivação para alcançar as realizações, os propósitos, as necessidades e os desejos, expressando seu potencial e servindo de equilíbrio entre os pensamentos positivos e negativos, aspectos significantes para a vida em geral, com pesquisas que demonstraram resultados positivos aos desempenhos da vida pessoal e profissionais quando os indivíduos 
possuíam estados psicológicos positivos (Farsen et al., 2018).

\subsection{A felicidade auto percebida e as dimensões que a compõem}

O entendimento sobre a felicidade pode ser definido a partir de tópicos temáticos, ou dimensões: psicológica, social e emocional (Barros-Oliveira, 2010).

Partindo desse suporte referencial, os dados a seguir estão estruturados nas perspectivas das dimensões psicológica, social e emocional.

\subsubsection{A felicidade auto percebida sob a perspectiva da dimensão psicológica}

A dimensão psicológica abriga a auto aceitação, o desenvolvimento pessoal, o ter finalidades na vida, o domínio do ambiente, a autonomia, e as relações positivas com os outros (SNYDER; LOPES, 2007).

Desse modo, os resultados e discussões a seguir são apresentados conforme cada item que compõe esta dimensão.

A auto aceitação foi percebida de forma positiva, pois $23(53,5 \%)$ participantes disseram ter boa aceitação e estar satisfeitos com si próprio fisicamente e psicologicamente.

E9 "Sim, eu me auto aceito, eu acho que sempre temos que melhorar, mas eu me aceito sim da forma que eu estou, lógico que a gente sempre tem que melhorar nas coisas".

E33 "Hoje em dia eu me aceito bem, eu consigo empoderar o que eu preciso melhorar e o que eu sou".

E37 "Melhorei muito nisso, hoje em dia me aceito muito mais como eu sou, não vejo problemas com meu corpo e minhas atitudes".

E41 "Eu aprendi a ter uma auto aceitação, amizades também me ensinaram isso, acho que toda mulher tem uma insegurança, mas eu aprendi a lidar com isso".

E foi considerada insatisfatória por 20 (46,5\%) participantes que afirmam não ter boa aceitação, alta cobrança, atitudes, inseguranças, exigências consigo mesmo, entre outros fatores.

E12 "Horrivel, eu não sei, comigo mesma eu sou bem crítica".

E28 "No momento está bem baixa, estou gorda, estou me sentindo mal, minha autoestima está lá embaixo".

E30 "Mais ou menos, porque tem coisas que eu quero fazer, mas eu não consigo, vou atrás, mas coisas me impedem”.

E43 "Péssima, não consigo me aceitar em nenhum aspecto, nem fisicamente, nem mentalmente, eu tenho um sério problema comigo mesmo assim".

Junto a isto, foi solicitado que transformassem seus depoimentos em uma nota de zero a 10 para o limiar de auto aceitação. As notas variaram de zero a 10, com média de 7,6.

As vivências fazem com que os jovens reflitam a respeito das suas atitudes e pensamentos, destacando a importância de não realizar julgamentos negativos em relação a suas próprias escolhas, o zelo, acolhimento e amor próprio contribui na auto aceitação. Estes fatores auxiliam nas habilidades, criatividades e valorização de si perante a sociedade (Kestenberg, 2016).

A liberdade e independência durante a vida acadêmica também colaboram para esta apreciação, as impressões e padrões 
impostos pela sociedade influenciam negativamente neste sentimento e satisfação pessoal (Silva, 2016).

Quando questionados sobre o crescimento pessoal, $41(95,4 \%)$ participantes consideraram positivos, afirmando estarem realizados e satisfeitos com os acontecimentos que estão ocorrendo em suas vidas.

E8 "Acho que bom, porque com o passar dos anos a gente vai evoluindo né. A gente crescer e amadurecer é bom, estou satisfeita".

E9 "Eu mudei muito e literalmente meu crescimento mudou junto comigo, então ele cresceu. Sim, estou satisfeita".

E15 "Muito bom, está acontecendo, porque quando eu estava na escola eu nunca tive essa visão de ai vou trabalhar, vou ajudar em casa, meus pais sempre escondeu bastantes coisas da gente sabe, ai depois do primeiro ano de faculdade que a gente passou umas dificuldades em casa que eu comecei a correr atrás das coisas, estou bastante satisfeita".

E41 "Evolui muito, en amadureci, aprendi a cuidar de mim, ajudar as pessoas que precisam sempre mais que eu. Estou satisfeita sim, no momento posso dizer que estou satisfeita. Mudei bastante as minhas atitudes e os tipos de pessoas que eu tenho perto de mim".

Por outro lado, 2 (4,6\%) participantes se consideraram insatisfatórios pois afirmam não estar alcançando o desenvolvimento esperado e que considera ser bom em sua vida.

E20 "Não sei, nem sempre tem acontecido, tem vezes que sou muito barrada pela minha família e pela sociedade, no sentindo de ter liberdade de fazer e falar tem coisas que eu não posso falar ou fazer, tem coisas que eu quero fazer, mas não dá. Nem sempre estou satisfeita, tem vezes que é para o meu bem, que vai fazer bem, mas não tem como fazer". E43 "Nossa isso eu tenho um sério problema sabe, eu me sinto muito velho para ainda estar na faculdade, porque já é quase minha terceira graduação, isso é uma coisa que mexe muito comigo e também por depender ainda dos meus pais, fico pensando que tenho já 28 anos, quase terceira graduação e não tenho nem minha dependência financeira, a onde eu estou ai me fala de crescimento pessoal e eu me sinto mal, incapaz mesmo com isso. Olhando assim para mim eu não estou satisfeito, agora olhando de fora outras pessoas acho que está bacana”.

Nisto, foi solicitado uma nota de zero a 10 para o seu crescimento pessoal. As notas variaram de três a 10, com média de 9,1 .

Os estudantes de enfermagem devem saber superar os obstáculos e desafios presentes diariamente em sua vida, contornando-os para obter um resultado favorável no final (Frenhan \& Silva, 2020) proporcionando a felicidade.

Superar os planos traçados demonstra os esforços, com celebrações e sentimentos positivos que motiva o aumento de potencial nos estudos e no ambiente de trabalho. As necessidades e forma de crescimentos e conquistas são individualizadas, com percepções diversas conforme o modo que cada estudando vivencia a vida, suas necessidades e experiências pessoais e profissionais (Prolo \& Arantes, 2018).

O próximo item abordado foi o controle de ambiente, sendo positivo para $26(60,4 \%)$ dos participantes, considerando sua capacidade de adaptação - resiliência, capacidade de domínio e mudança dos condicionantes ambientais, como podemos observar nas falas:

E4 "Sou uma pessoa que me adapto muito fácil, tenho uma fácil adaptação em diferentes lugares, diferentes pessoas, 
por mais que seja um ambiente que não me faça tão bem, demora um pouco, mas eu me adapto".

E8 "Acho que qualquer mudança que tiver, eu sou super aberta para mudanças, também não tenho problema nenhum com isso".

E33 "Eu me adapto bem com mudanças, é tranquilo, a gente tem os momentos humanos, mas geralmente me adapto bem".

Já 17 (39,6\%) participantes consideraram estar insatisfeitos com sua capacidade de adaptação, ocorrendo dificuldades com mudanças e domínios, necessitando de um tempo para habituar-se.

E13 "As mudanças trazem muitos conflitos em si né, porém como dizemos a questão do respeito, o tempo é a única resposta se será algo positivo ou negativo e isso geram conflitos".

E23 "Eu tenho, tanto se for viajar ou trabalhar, eu não sou nômade, parece que eu crio raiz naquele lugar, para mim é bem dificultoso, já fui à psicóloga, estou tratando isso, não consigo, é bem difícil o recomeço e a mudança para mim”.

E27 "Com mudanças eu sofro um pouco para me adaptar, aí depois que vou me encaixando e resolvendo meu pensamento e minha mente".

Quando solicitado que os participantes, transformassem seus depoimentos em uma nota de zero a 10 para o limiar de controle do ambiente. As notas variaram de quatro a 10, com média de 7,8.

As adaptações geram melhores desempenhos práticos do indivíduo, a busca por conhecimentos facilita neste processo e minimiza possíveis problemas. O processo de transição às vezes se faz necessário para o indivíduo se adequar com as novas descobertas e mudanças (Dummer, Souza, Carvalho, \& Rocha, 2018) que prepara os graduandos para o ingresso ao mercado de trabalho, ocorrendo tensões e mudanças que decaem sobre os vínculos e conviveu das pessoas e dos familiares, um bom ambiente e sua adaptação é fundamental para o desenvolvimento profissional (Frenhan \& Silva, 2020).

Posteriormente quando questionados sobre sua autonomia, a mesma foi considerada positiva para $26(60,4 \%)$ participantes com autodeterminação, liberdade, independência e autocontrole do comportamento.

E5 "Boa, porque eu sou independente, eu faço o que eu quero, o que eu não quero eu não faço".

E22 "Eu sou bem autônoma, não fico esperando ninguém fazer nada para mim".

E23 "Eu sou uma pessoa livre, sou casada, mas tenho a minha liberdade, no meu emprego eu gosto do que eu faço então me sinto livre".

E24 "Boa, porque eu acho que não tem nada específico que me prende, eu faço tudo o que tenho vontade, só as questões financeiras que segura um pouco".

E36 "Pergunta difícil, não sei explicar, mas faço sim tudo o que eu quero, tenho dependência, só que minha liberdade não tem quem controle, eu me auto controlo, mas eu penso "será que tipo se eu fizer tal coisa, a consequência não vai ser tal?". Acho que por isso ninguém nunca ficou no meu pé porque eu mesma me auto policio".

Mas $17(39,6 \%)$ participantes estão insatisfeitos, pois afirmam ter restrições no comportamento por influência e 
autoridade de familiares e da sociedade que atrapalham em sua autonomia.

E19 "É assim, eu sozinha eu sou quem eu sou, eu gosto de rir, brincar, eu brinco com os meninos e tudo, mas quando o meu marido está perto eu tenho que diminuir um pouco, me retrair, tenho que dar uma segurada, não posso brincar com os meninos igual eu brinco, na frente dele assim".

E20 "Isso já é um caso meio complicado, porque eu tenho muitas restrições, de poder fazer as coisas, sou muito restrita em relação aos meus pais".

E43 "Pela falta de independência ainda que eu tenho, mas pela dependência financeira mesmo, pela faculdade, mesmo que eu trabalho eu dependo do meus pais ainda para muitas coisas, mesmo ainda estando numa união estável ainda tenho a ajuda do meu marido mas ainda preciso da ajuda dos meus pais para muitas coisas".

Junto a isto, os seus depoimentos em uma nota de zero a 10 para o limiar de autonomia. As notas variaram de cinco a 10, com média de 8,5. As notas apresentaram justificativas:

Na vida acadêmica ocorrem mudanças, e para alguns indivíduos a primeira vez em que exerce a autonomia é na escolha e transição do ensino médio para o ensino superior. Durante esta fase de sua vida, aguarda-se que os mesmos possam se posicionar perante seus aprendizados, suas escolhas, definir o tempo para estudos e para atividades pessoais, traçar metas e táticas para obtenção do êxito (Anversa, Santos, Silva, \& Fedosse, 2018).

Posteriormente devem ocorrer as escolhas e determinações na pós vida acadêmica e a inserção na vida profissional na área de formação, demonstrando que toda etapa da vida se faz necessário ser autônomo, livre, determinado e saber se auto policiar (Anversa et al., 2018).

\subsubsection{A felicidade sob a perspectiva da dimensão social}

A dimensão social contém a aceitação (importância pessoal nos grupos), atualização e contribuição social, coerência e integração social (Snyder \& Lopes, 2007).

Diante disto, os resultados e discussões a seguir são apresentados conforme cada item que compõe esta dimensão.

As relações sociais foram positivas para $39(90,7 \%)$ participantes, que afirmaram ter boa capacidade de relações interpessoais calorosas, de empatia, de intimidade, de amar e de fazer amizades.

E11 "Super positivas, eu consigo criar assim esse vínculo de empatia com as pessoas, mesmo que eu não conheço, graças a Deus não tenho esse problema não".

E23 "Positivas, eu trabalho num lugar que tem muito acolhimento então a gente aprende a lidar com está parte da empatia, simpatia".

E24 "Positivas, porque eu acho que sou muito carismática, me dou bem com todo mundo".

E26 "Positivas, sou uma pessoa bem extrovertida, bem aberta para conhecer pessoas, bem amiga com as pessoas que já conheço".

E40 "Positivas, eu não sou muito extrovertida, mas eu consigo me relacionar bem, eu sei me comunicar, então dá para estabelecer uma relação bem legal". 
E $4(9,3 \%)$ participantes consideraram parcialmente negativos, insatisfeitos, pois afirmam que a timidez, seus comportamentos e a interação atrapalham nestes relacionamentos.

E17 "Sou meio dificil de fazer amizades porque eu sou um pouco quieta, a pessoa que tem que puxar assunto, mas depois que começa conversar dai de boa".

E30 "Depende da pessoa, tenho empatia, mas tem gente que não desce, depende das pessoas, mas acho que positivas".

E32 "Razoáveis, pois sou muito tímida e isso atrapalha".

E36 "Depende, em partes, eu tenho muita dificuldade para interagir por ser vergonhosa, tímida, essas coisas, então me impede um pouco, mas em geral depois que acaba a timidez é positiva”.

Na transformação de seus depoimentos em uma nota de zero a 10 para as relações positivas. As notas variaram de sete a 10 , com média de 8,9 .

Uma boa relação social facilita o processo de adaptação universitária e profissional, demonstrando em estudos que quanto maior sua interação social, maior o seu sentimento de felicidade. As instituições contam com estás habilidades sociais para ocorrer à interação e o bom relacionamento entre os discentes e os docentes (Lima, Soares, \& Souza, 2019).

A relação com os amigos, novos colegas, os familiares, o ambiente e colega de trabalho e da faculdade com emoções e sentimentos positivos traz a percepção de bem estar além de social também físico e mental (Rodrigues, Silva, \& Souza, 2019).

$\mathrm{Na}$ dimensão psicológica, a avaliação positiva foi observada na maioria dos itens, fato evidenciado nos relatos dos entrevistados em possuir boa aceitação física e das suas atitudes, o crescimento pessoal através de superação das dificuldades encontradas, as evoluções, as fáceis adaptações às mudanças e a crescente independência, determinação e amadurecimento ao longo da graduação, itens que em sintonias de forma positivas mesmo com os desafios de transição encontrados durante a vida acadêmica, elevam os níveis de felicidade e contribuem para o desenvolvimento e formação de profissionais competentes, otimistas, responsáveis, determinados para tomadas de decisões (Oliveira, Merino, Privado, \& Almeida, 2018), com grandes potenciais de aprimoramentos e habilidades.

O indivíduo quando determinado em ter bons relacionamentos pessoais e sociais, evidencia uma boa saúde psicossocial e consequentemente a melhora do seu bem-estar psicológico, pois o nível de felicidade pode influenciar em todo seu comportamento universitário (Granja \& Mota, 2018).

\subsubsection{A felicidade sob a perspectiva da dimensão emocional}

A dimensão emocional abarca as experiências positivas e ausência das experiências negativas, a satisfação com a vida e sentimentos positivos (Snyder \& Lopes, 2007).

Desse modo, os resultados e discussões a seguir são apresentados conforme cada item que compõe esta dimensão.

Ao questionar os sentimentos mais frequentes em sua vida e a satisfação com a vivência desses sentimentos, 19 (44,1\%) participantes relataram ter sentimentos positivos, com algumas justificativas:

E5 "Mais felicidade, porque eu estou fazendo as coisas que eu gosto, eu tenho as pessoas que eu gosto ao meu lado, eu tenho amigos, eu tenho a minha mãe do meu lado para tudo, meus irmãos. Sou satisfeita com este sentimento".

E13 “Acho que fé, devido a tudo, a questão familiar também conta muito, a minha fé cresceu muito devido a minha família e é algo que eu busco diariamente na igreja, é algo que só tem a acrescentar em minha vida. Com certeza estou 
satisfeita".

E20 "Sou uma pessoa alegre, que gosto de motivar as outras pessoas, não sei falar o porquê, mas sou satisfeita com está alegria".

E24 "Gratidão, felicidade, determinação, coragem. Porque estou trabalhando muito isso para não ficar muito procrastinado, estou ficando satisfeita, porque antes não era".

E30 "Felicidade, porque tudo que vem acontecendo agora é o que eu almejei. Estou satisfeita".

E 24 (55,9\%) participantes declararam sentimentos negativos sendo os mais frequentes e/ou desagrado com a vivência deste sentimento no seu cotidiano, como justificado em algumas falas:

E2 "Morte, as pessoas que convivo não me deixa livre, não estou nada satisfeita".

E4 "Estresse, por conta do momento que está sendo vivido agora, e não estou nem um pouco satisfeita, depois desse momento passando talvez o motivo possa mudar".

E22 "Ansiedade, do nada eu sou muito ansiosa, qualquer coisa me deixa ansiosa. Com qualquer coisa, sem motivos especificos, não sou satisfeita com isso".

E27 "Sinto um pouco de medo, medo do futuro. Não estou satisfeita, não queria, acho que o medo me atrapalha em muitas coisas".

E32 "Paciência, que é uma coisa que eu não estou tendo há muito tempo e eu acabo descontando nas pessoas em volta, estou tendo muita raiva. Não estou satisfeita, está bem complicado".

E36 "Preocupação, se eu vou dar conta da faculdade, se eu vou conseguir pagar até o final, conseguir tirar nota, essas são minhas maiores preocupações do momento. Não estou satisfeita, pois queria estar tranquila”.

E43 "Ultimamente acho que é mais insatisfação, ansiedade, preocupação. Acho que pelo momento que estou vivendo mesmo, o último ano da faculdade. Não queria estar me sentindo assim, estou tentando lutar contra isso na verdade".

A faculdade provoca desgastes sentimentais como ansiedade, incertezas, decepções, receios, angústias, entre outros fatores emocionais que atingem a qualidade de vida e prejudica a capacidade cognitiva e assistencial. A sobrecarga de afazeres em conciliar a vida acadêmica, pessoal e familiar atrapalha a alimentação, o lazer, a realização de atividades físicas e o descanso necessário provocando uma baixa imunidade e concentração dos estudantes (Viana \& Sampaio, 2019). A boa comunicação evita estes desgastes e o surgimento de sentimentos e doenças que refletem negativamente na saúde (Vilela \& Lourenço, 2019) dos indivíduos.

Os estudantes quando apresentam sentimentos positivos, como a felicidade, manifestam maior valorização da vida pessoal e acadêmica, demonstrando potencial para executar as atividades propostas com exatidão, traçar planos e determinar metas com baixa possibilidade de desleixar perante os obstáculos (Reppold et al., 2019).

\section{Considerações Finais}

Durante a vida acadêmica os jovens sofrem com as diversas mudanças pessoais, profissionais e de aprendizados, dedicações e avaliações exigidas pela universidade por ser um local fundamental em promover habilidades e capacitações aos 
graduandos.

Nas etapas do curso, principalmente as de transição do ensino médio para o superior, início dos estágios supervisionados e a reta final de conclusão da graduação geram um misto de sensações como liberdade, autonomia, ansiedade, medo, entre outros sentimentos.

Deste modo, a felicidade, estado considerado positivo, pode interferir significantemente de forma favorável nas atitudes, sentimento este de satisfação e transformação das emoções em valorização da vida, contudo, cada indivíduo tem sua forma de expressar e se relacionar, sendo um parâmetro de relações familiares e sociais ou também para alguns, um parâmetro individualista, destacando que todos os estudantes foram capazes de identificar as razões de sua felicidade ou infelicidade.

Como nas dimensões psicológicas, a felicidade se demonstrou presente através das aceitações de comportamentos e fisicamente de sua aparência, as conquistas e amadurecimento com os crescimentos pessoais e os planos traçados sendo obtidos a partir do ingresso universitário, a facilidade de adaptação e domínio as mudanças principalmente durante esta fase em que se encontram e a autonomia para executar seus planos sem interrupções, fatores que em conjunto trazem esperanças em continuar se dedicando em busca de sua formação profissional. Por outro lado, as cobranças pessoais, familiares e da sociedade, as inseguranças, a necessidade de um tempo para planejamento das mudanças e adaptações e as restrições das ações influenciando negativamente na autonomia são causas que abalam o psicológico dos indivíduos.

A felicidade destes graduandos na dimensão social é observada pela facilidade em se relacionar em diversas ocasiões, com diferentes públicos, criando vínculos e respeitos, principalmente no âmbito profissional da enfermagem em que o acolhimento dos enfermos e da prevenção e promoção à saúde se fazem de suma importância. Porém, a timidez e as desigualdades, se presentes no indivíduo, interferem nesta interação social de forma negativa.

Os sentimentos frequentes na dimensão emocional destacam-se em sua maioria o da felicidade, sendo indivíduos otimistas para enfrentar os desafios que surgirem ao longo do percurso da graduação e posteriormente profissional. Entretanto, a ansiedade, a tristeza e a preocupação com o futuro desencadeiam receios em executar as ações planejadas.

Apesar das dificuldades e limitações presentes e identificadas pelos estudantes de enfermagem durante a formação acadêmica, conclui-se que a preservação e apoio da sanidade mental destes indivíduos se faz necessária pela colaboração das instituições através de seus gestores e docentes com promoções e ações para a redução de agravos. o autoconhecimento e equilíbrio dos graduandos para a prevenção de sua saúde e os riscos decorrentes das vulnerabilidades, visando na contribuição do desenvolvimento físico, mental e social para a formação de um indivíduo capacitado para superar os obstáculos presentes diariamente de maneira saudável em seu estado positivo e para o seu bem-estar.

\section{Referências}

Afonso, M. L. M., Rodrigues, M., \& Oliveira, E. F. (2018). Juventude universitária e direitos de cidadania: sentidos atribuídos à diversidade sexual. Cad. Pesqui., 48(169), 948-972. https://doi.org/10.1590/198053145364.

Anversa, A. C., Santos, V. A. V. F., Silva, E. B., \& Fedosse, E. (2018). Qualidade de vida e o cotidiano acadêmico: uma reflexão necessária. Cadernos Brasileiros de Terapia Ocupacional, 26(3), 626-631. https://doi.org/10.4322/2526-8910.ctoAO1185

Bardin, L. (2011). Análise de Conteúdo. Edições 70 Ltda.

Barros-Oliveira, J. H. (2010). Felicidade, optimismo, esperança e perdão em jovens, adultos e idosos. Psychologica, 52(1), 123-148. https://doi.org/10.14195/1647-8606_52-1_7.

Campos, M. O. \& Rodrigues Neto, J. F. (2008). Qualidade de vida: um instrumento para promoção de saúde. Revista Baiana de Saúde Pública, 32(2), 232-240.

Carleto, C. T., Cornelio, M. P. M., Nardelli, G. G., Gaudenci, E. M., Haas, V. J., \& Pedrosa, L. A. K. (2019). Saúde e qualidade de vida de universitários da área da saúde. REFACS, 7(1), 53-63. https://doi.org/10.18554/refacs.v7i1.2966

Cestari, V. R. F., Barbosa, I. V., Florêncio, R. S., Pessoa, V. L. M. P., \& Moreira, T. M. M. (2017). Estresse em estudantes de enfermagem: estudo sobre vulnerabilidades sociodemográficas e acadêmicas. Acta Paulista de Enfermagem, 30(2), 190-196. https://dx.doi.org/10.1590/1982-0194201700029 
Conselho Federal de Enfermagem (2017). Relatório final da Pesquisa Perfil da Enfermagem no Brasil - FIOCRUZ. http://www.cofen.gov.br/perfilenfermagem/index.html\#: :text=A\%20Pesquisa\%20Perfil\%20da\%20Enfermagem,Enfermagem\%20em\%20atua\%C3\%A7\%C3 $\%$ A3o\%20no\%20Brasil.

Dummer, M. C. R., Souza, M. M., Carvalho, N., \& Rocha, L. Q. (2018). A relevância da pesquisa científica para o graduando de administração: análise da percepção dos discentes. Cadernos da Fucamp, 17(31), 64-79.

Eufrazio, J. P., Batiston, A. P., \& Medeiros, A. A. (2019). Caracterização do estilo de aprendizagem de graduandos em enfermagem do campus de Campo Grande da Universidade Federal de Mato Grosso Do Sul. Rev. Cadernos de Educação, Saúde e Fisioterapia, 6(12).

Facioli, A. M., Barros, Â. F., Melo, M. C., Ogliari, I. C. M., \& Custódio, R. J. (2019). Depressão entre estudantes de enfermagem e sua associação com a vida acadêmica. Revista Brasileira de Enfermagem, 73(1), e20180173. https://doi.org/10.1590/0034-7167-2018-0173

Farsen, T. C., Boehs, S. T. M., Ribeiro, A. D. S., Biavati, V. P., \& Silva, N. (2018). Qualidade de vida, Bem-estar e Felicidade no Trabalho: sinônimos ou conceitos que se diferenciam? Interação em Psicologia, 22(1), 31-41. http://dx.doi.org/10.5380/psi.v22i1.48288.

Frenhan, M. \& Silva, D. A. (2020). Avaliação da qualidade de vida em estudantes de enfermagem. Research, Society and Development, 9(5), e37953105. https://doi.org/10.33448/rsd-v9i5.3105

Granja, M. B. \& Mota, C. P. (2018). Estilos parentais, adaptação académica e bem-estar psicológico em jovens adultos. Aná. Psicológica, 36(3), 311-326. https://doi.org/10.14417/ap.1415.

Kestenberg, C. C. (2016). Cuidando do graduando e ensinando relações de Cuidado - algumas reflexões. Revista Aproximando, 2(3).

Lima, C. A., Soares, A. B., \& Souza, M. S. (2019). Treinamento de habilidades sociais para universitários em situações consideradas difíceis no contexto acadêmico. Psicol. clin., 31(1), 95-121. https://doi.org/10.33208/PC1980-5438v0031n01A05

Mezzomo, F. A., Pátaro, C. S. O., \& Bonini, L. F. G. (2018). "Não tenho religião, apenas a crença em Deus": trajetórias e compreensões religiosas de jovens universitários. Revista Brasileira de História das Religiões, 11(33), 233-266. https://doi.org/10.4025/rbhranpuh.v11i33.43487.

Moura, I. H., Nobre, R. S., Cortez, R. M. A., Campelo, V., Macedo, S. F., \& Silva, A. R. V. (2016). Qualidade de vida de estudantes de graduação em enfermagem. Revista Gaúcha de Enfermagem, 37(2). https://doi.org/10.1590/1983-1447.2016.02.55291

Nunes, M., Lunardi, W., Rasi, L., Tu, R., Aparecido, A. Y., \& Souza, J. (2014). Qualidade de vida de estudantes de enfermagem. Revista da Rede de Enfermagem do Nordeste, 15(6), 990-997. http://dx.doi.org/10.15253/2175-6783.2014000600012.

Oliveira, E. P., Merino, M. D., Privado, J., \& Almeida, L. S. (2018). Escala de Funcionamento Psicológico Positivo. Revista Iberoamericana de Diagnóstico y Evaluación e Avaliação Psicológica. 48. https://doi.org/10.21865/RIDEP48.3.13.

Osório, C. (2016). Os Sete Princípios da Felicidade proposto por Archor e a prática dos líderes de sua equipe. (Trabalho de Conclusão de Curso). Universidade do Vale do Rio dos Sinos, Porto Alegre.

Pais-Ribeiro, J. L. (2012). Felicidade, bem-estar, qualidade de vida e saúde. Psicologia na Actualidade, 8, 22-31.

Pereira, A. S., Shitsuka, D. M., Parreira, F. J., \& Shitsuka, R. (2018). Metodologia da pesquisa científica. [e-book]. Santa Maria. Ed. UAB/NTE/UFSM. : em: https://repositorio.ufsm.br/bitstream/handle/1/15824/Lic_Computacao_Metodologia-Pesquisa-Cientifica.pdf?sequence=1

Pereira, V. S., Reis, D. A., \& Oliveira, S. A. (2019). Fatores de risco para desenvolvimento de diabetes mellitus do tipo 2 em estudantes universitários do curso de enfermagem do interior do Amazonas. Revista Eletrônica Acervo Saúde, 11(4), e1033. https://doi.org/10.25248/reas.e1033.2019.

Petry, S., Padilha, M. I., Kuhnen, A. E., \& Meirelles, B. H. S. (2019). Saberes de estudantes de enfermagem sobre a prevenção de Infecções Sexualmente Transmissíveis. Revista Brasileira de Enfermagem, 72(5), 1145-1152. https://dx.doi.org/10.1590/0034-7167-2017-0801

Preto, V. A., Souza, A. L. T., Sousa, B. O. P., Fernandes, J. M., Pereira, S. S., \& Cardoso, L. (2020). Preditores de estresse recente em universitários de enfermagem. Research, Society and Development, 9(3), e37932371. https://doi.org/10.33448/rsd-v9i3.2371

Prolo, I. \& Arantes, D. D. (2018). Expressões de felicidade no trabalho organizacional: estudo com executivos, profissionais graduados e não-graduados. Caderno Profissional de Administração - UNIMEP, 8(2).

Reppold, C., Kaiser, V., Zanon, C., Hutz, C., Casanova, J. R., \& Almeida, L. S. (2019). Escala de Satisfação com a Vida: Evidências de validade e precisão junto de universitários portugueses. Revista de estudios e investigación en psicología y educación, 6(1), 15-23. https://doi.org/10.17979/reipe.2019.6.1.4617.

Ribeiro, C. A. C. (2015). Renda, Relações Sociais e Felicidade no Brasil. Revista de Ciências Sociais, 58(1), 37-78. http://dx.doi.org/10.1590/00115258201538.

Ribeiro, R. M., Bragiola, J. V. B., Eid, L. P., \& Pompeo, D. A. (2019). Impacto da autoestima e dos fatores sociodemográficos na autoeficácia de estudantes de graduação em enfermagem. Texto contexto - enferm., 29, e20180429. https://doi.org/10.1590/1980-265x-tce-2018-0429.

Rodrigues, D. S., Silva, B. O., \& Souza, M. B. C. A. (2019). Análise da Qualidade de Vida de Estudantes Universitários da Área de Saúde. Revista Saúde em Foco, 6(2), 3-16. https://doi.org/10.12819/rsf.2019.6.2.1.

Rossini, A. M. \& França, A. C. L. (2014). A educação e o uso sustentável das tecnologias. uma discussão sobre o aprendizado a distância, as redes sociais e a educomunicação. RISUS - Journal on Innovation and Sustainability, 5(3), 4-23. https://doi.org/10.24212/2179-3565.2014v5i3p4-23

Snyder, C. R. \& Lopes, S. J. (2007). Psicologia positiva: As explorações científicas e práticas das forças humanas. Thousand Oaks, CA, Sábio. 
Research, Society and Development, v. 10, n. 2, e27610212505, 2021

(CC BY 4.0) | ISSN 2525-3409 | DOI: http://dx.doi.org/10.33448/rsd-v10i2.12505

Santos Júnior, A., Rachkorskyv, L. L., Ronzoni, P., Dogra, N., \& Dalgalarrondo, P. (2017). Experiências percebidas de discriminação e Saúde Mental: resultados em estudantes universitários brasileiros. Serviço Social e Saúde, 15(2), 273-298. https://doi.org/10.20396/sss.v15i2.8648121.

Silva, A. W. F. (2016). Autoaceitação, aceitação sócio-familiar e saúde sexual de jovens homossexuais (do sexo biológico masculino) no maciço de Baturité. (Trabalho de Conclusão de Curso), Instituto de Ciências da Saúde, Universidade da Integração Internacional da Lusofonia Afro-brasileira, Acarape.

Silva, B. L. G., Alves, E. S., \& Fortes, A. F. A. (2019). Percepção de estudantes de enfermagem sobre o que é ser enfermeiro. Arq. Cienc. Saúde UNIPAR, 23(2), 81-88. https://doi.org/10.25110/arqsaude.v23i2.2019.6136.

Simoes, A. V., Penna, L. H. G., Rodrigues, V. P., Carinhanha, J. I., Pereira, A. L. F., \& Machado, J. C. (2019). Relações afetivas íntimas de jovens universitários: narrativas de estudantes de enfermagem. Revista Enfermagem UERJ, 27, e34355. https://doi.org/10.12957/reuerj.2019.34355.

Urbanetto, J. S., Rocha, P. S., Dutra, R. C., Maciel, M. C., Bandeira, A. G., \& Magnago, T. S. B. S. (2019). Estresse e sobrepeso/obesidade em estudantes de enfermagem. Revista Latino-Americana de Enfermagem, 27, e3177. https://doi.org/10.1590/1518-8345.2966.3177

Viana, A. G. \& Sampaio, L. (2019). Qualidade de Vida dos Universitários em período de Conclusão de Curso. Rev. Mult. Psic., 13(47), 1085-1196. https://doi.org/10.14295/idonline.v13i47.2106.

Vilela, N. G. S. \& Lourenço, M. L. (2019). Déficit de habilidades sociais: análise da percepção de estudantes universitários. Revista Eletrônica Ciências da Administração e Turismo, 7(1), 1-12. 